\title{
Strength of clean indoor air laws and smoking related outcomes in the USA
}

\author{
K M McMullen, R C Brownson, D Luke, J Chriqui
}

See end of article for authors' affiliations

....................

Correspondence to: Mrs Kathleen M McMullen, Infection Control, BarnesJewish Hospital, One Barnes-Jewish Hospital Plaza, Mailstop 90-30632, St Lovis, Missouri 63110, USA;

pebpegasus@yahoo.com

Received 23 February 2004 Accepted 30 August 2004
Objectives: Environmental tobacco smoke (ETS) is often encountered in the workplace. There have been efforts to apply and enforce state laws limiting workplace smoking. There has been little study of the relative effectiveness of state and/or local laws in affecting both rates of workplace ETS exposure and adult smoking rates. This study investigates these hypotheses, as well as the effect of these laws on youth smoking.

Design: This is a secondary data analysis using sources including the Current Population Survey (CPS), Behavioral Risk Factor Surveillance System (BRFSS), Youth Risk Behavior Survey (YRBS), and the National Household Survey of Drug Abuse (NHSDA) between the years of 1996 and 1999. Linear regression models were used to investigate the effect of a state's clean indoor air (CIA) law (using a measure of extensiveness) on the overall amount of people who reported working in a smoke-free environment, youth smoking rates and adult smoking rates.

Results: The extensiveness of a state's CIA law was found to be a reliable predictor of the percentage of indoor workers who report a smoke-free work environment and the rates of youth smoking. State CIA laws were not conclusively associated with adult smoking rates.

Conclusions: The extensiveness of a state's CIA law is strongly associated with a higher percentage of indoor workers reporting a smoke-free work environment. This study did not reveal a similar association between local laws and smoke-free work environments. Youth smoking rates, shown to be related to state $\mathrm{CIA}$ laws, may be further affected with more stringent CIA policy.
E xposure to environmental tobacco smoke (ETS) is a major health concern, resulting in increased risk of lung cancer, childhood respiratory tract ailments, and heart disease in non-smokers. ${ }^{12}$ An acceptable threshold has not been set for ETS exposure ${ }^{3}$ although ETS is listed as a known human carcinogen, for which there is no general standard of acceptable exposure. ${ }^{1}$

The workplace is a major source of ETS exposure. ${ }^{4}$ One study using exposure diaries for 186 people concluded that half of daily ETS exposure can be attributed to the workplace. ${ }^{5}$ This and other studies have shown multiple reasons to restrict ETS in the workplace: ETS accounts for around 28000 deaths of lung cancer and heart disease annually, ${ }^{1}$ can be bothersome and discomforting, ${ }^{6}$ increases maintenance and repair costs while decreasing productivity of workers, ${ }^{7}$ causes employers to face liability for nonsmoker's health, ${ }^{7}$ restricting ETS encourages smokers to reduce or quit smoking, ${ }^{8}$ and ETS control efforts may lead to changes in domestic environments and youth smoking rates. ${ }^{9}$

There have been several initiatives to limit workplace ETS. US policies have outlawed smoking on airplanes, ${ }^{10}$ in federal office buildings, including the White House, ${ }^{11}$ and in day care facilities that receive federal funds. ${ }^{12}$ As of 1998, 20 states had limited smoking in private workplaces. As of 2003, California, Delaware, New York, Connecticut, Florida, and Maine have completely banned indoor smoking or limited it to areas with separate ventilation, ${ }^{13}$ and approximately 1609 local ordinances restrict public smoking in the USA. ${ }^{3}$ The movement toward tougher ETS worksite restrictions has been growing. A Healthy People 2010 goal is to establish laws on smoke-free indoor air that prohibit smoking or limit it to separately ventilated areas in public places and worksites. ${ }^{14}$
The results of research on ETS laws in the form of workplace policies and their effects on consumption of cigarettes, adult smoking prevalence, and smoking cessation have been somewhat varied. ${ }^{85-19}$ Researchers consistently agree that worksite policies decrease the number of cigarettes consumed by smokers, at least on working days. ${ }^{15-18}$ Studies also claim that workplace policies reduce the prevalence of smokers or increase cessation attempts by workers. ${ }^{815}{ }^{16}$ One study demonstrated that adult smoking decreased 1.2 cigarettes per day in a two year period after implementation of an ETS law. ${ }^{20}$ There is agreement that workplaces with total smoking bans, rather than partial smoking restrictions, tend to show a higher reduction in ETS exposure. ${ }^{815} 1921$ The effects that ETS laws in the workplace may have on youth smoking are uncertain, although recent cross sectional data are encouraging. ${ }^{22}$ Little is known about how statewide and/ or local ETS policies are related to exposure to clean indoor air (CIA) in the worksite and smoking prevalence among both adults and youths.

The purposes of this paper are twofold: (1) to assess the effects of state level ETS policies on self reported proportion of indoor workers exposed to ETS; and (2) to assess the potential effects of this measure of CIA policies on youth and adult smoking when controlling for other factors. The results of this paper are intended to add to the body of evidence supporting further CIA laws.

Abbreviations: ANRF, American Nonsmoker's Rights Foundation; BRFSS, Behavioral Risk Factor Surveillance System; CDC, Centers for Disease Control and Prevention; CIA, clean indoor air; CPS, Current Population Survey; ETS, environmental tobacco smoke; NCI, National Cancer Institute; NHSDA, National Household Survey of Drug Abuse; SCLD, State Cancer Legislative Database; TUS, tobacco use supplement; YRBS, Youth Risk Behavior Survey 


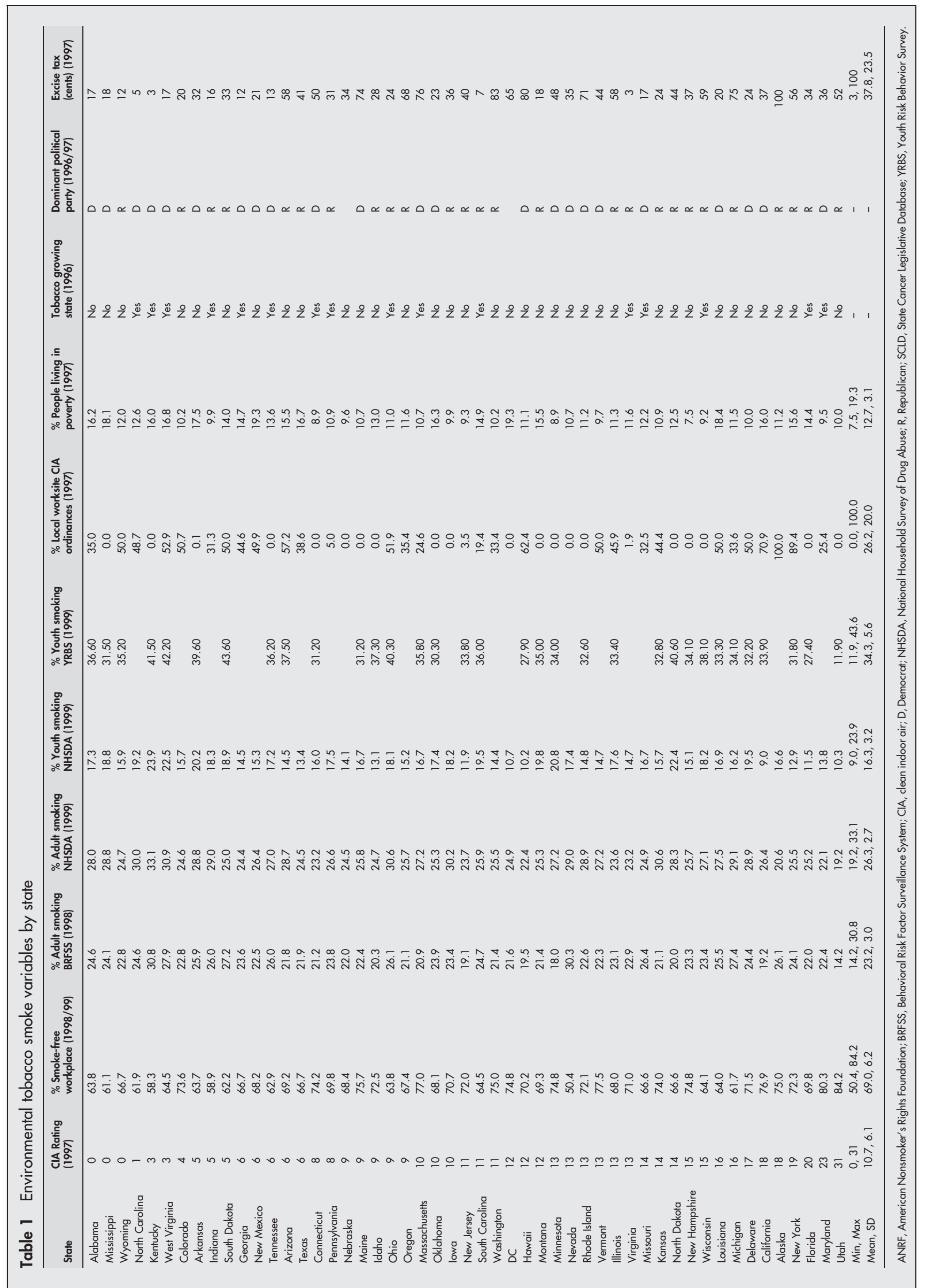


Table 2 Linear regression models for percentage smoke-free, youth smoking, and adult smoking $(n=51)$

\begin{tabular}{|c|c|c|c|c|c|c|c|c|c|c|c|c|c|c|c|}
\hline \multirow[b]{2}{*}{ Predictor variables } & \multicolumn{3}{|c|}{$\begin{array}{l}\text { Model 1: dependent } \\
\text { variable: \% smoke- } \\
\text { free }\end{array}$} & \multicolumn{3}{|c|}{$\begin{array}{l}\text { Model 2: dependent } \\
\text { variable: BRFSS adult } \\
\text { smoking }(\%)\end{array}$} & \multicolumn{3}{|c|}{$\begin{array}{l}\text { Model 3: dependent } \\
\text { variable NHSDA adult } \\
\text { smoking }(\%)\end{array}$} & \multicolumn{3}{|c|}{$\begin{array}{l}\text { Model 4: dependent } \\
\text { variable: NHSDA youth } \\
\text { smoking (\%) }\end{array}$} & \multicolumn{3}{|c|}{$\begin{array}{l}\text { Model 5: dependent } \\
\text { variable: YRBS youth } \\
\text { smoking (\%) }\end{array}$} \\
\hline & $\beta$ & SE & p Value & $\beta$ & SE & p Value & $\beta$ & SE & p Value & $\beta$ & SE & p Value & $\beta$ & SE & p Value \\
\hline Constant & 65.6 & 4.2 & - & 24.5 & 2.2 & - & 27.8 & 2.0 & - & 21.1 & 2.3 & - & 41.5 & 5.16 & - \\
\hline SCLD CIA score & 0.42 & 0.13 & 0.00 & -0.10 & 0.07 & 0.07 & -0.16 & 0.06 & 0.01 & -0.19 & 0.08 & 0.01 & -0.53 & 0.14 & 0.00 \\
\hline $\begin{array}{l}\text { ANRF local worksite } \\
\text { CIA (\%) }\end{array}$ & 0.01 & 0.03 & 0.72 & 0.02 & 0.02 & 0.25 & -0.03 & 0.02 & 0.09 & -0.01 & 0.02 & 0.40 & 0.02 & 0.05 & 0.76 \\
\hline Persons below & -0.27 & 0.26 & 0.30 & 0.06 & 0.14 & 0.67 & -0.01 & 0.02 & 0.41 & -0.10 & 0.15 & 0.48 & -0.02 & 0.04 & 0.61 \\
\hline $\begin{array}{l}\text { Excise tax (cents) } \\
R^{2}\end{array}$ & $\begin{array}{l}0.06 \\
0.36\end{array}$ & 0.04 & 0.11 & $\begin{array}{r}-0.03 \\
0.21\end{array}$ & 0.02 & 0.16 & $\begin{array}{l}0.11 \\
0.26\end{array}$ & 0.13 & 0.40 & $\begin{array}{r}-0.03 \\
0.25\end{array}$ & 0.02 & 0.14 & $\begin{array}{r}-0.05 \\
0.44\end{array}$ & 0.32 & 0.87 \\
\hline
\end{tabular}

ANRF, American Nonsmoker's Rights Foundation; BRFSS, Behavioral Risk Factor Surveillance System; CIA, clean indoor air; NHSDA, National Household Survey of Drug Abuse; SCLD, State Cancer Legislative Database; SE, standard error; YRBS, Youth Risk Behavior Survey.

\section{METHODS \\ Measures}

\section{$\mathrm{ClA}$ rating for states}

The National Cancer Institute's (NCI) State Cancer Legislative Database (SCLD) programme has maintained a state cancer related legislation database since $1989 .{ }^{23}$ In 2002 , Chriqui et al used this database to establish a measure of the extensiveness of state CIA laws for each state and Washington DC, between 1993 and 1999. ${ }^{24}$ Each state received a summary score, which was determined by summing the scores of each state in nine separate categories, including government worksites, private worksites, schools, childcare facilities, restaurants, retail stores, recreational/ cultural facilities, penalties and enforcement. Each individual category had a "target" score of +4 , reflecting the goal that the site be $100 \%$ smoke-free, or that the penalties and enforcement be the toughest. In six of the categories, a state could receive a "bonus" point (increasing the score to +5 ) for such things as requiring that all grounds surrounding the worksite be $100 \%$ smoke-free or requiring that child care facilities (explicitly including home based facilities) are 100\% smoke-free during operating hours. Taking these bonuses into account, the maximum score a state could receive was 42.

The SCLD ratings were constructed by two independent raters, then the ratings were compared and coded to form a final rating. ${ }^{24}$ In addition, a third rater tested the process, which was found to be reliable, with an interrater agreement of 0.86 .

The state scores increased from 1993 (average 8.71) to 1999 (average 10.98). Our study used the data from 1997, where the mean score was 10.7, and ranged from 0-31. In addition, our study also used a second set of scores that included preemption deductions. Pre-emption occurs when the state CIA laws supersede local CIA laws, and could be a major barrier to the enactment of local CIA laws. A two point deduction was given in all categories for a state law that uniformly preempted all local ordinances related to the CIA items of interest. This lowered the score for 16 states by between 1 and 17 points, resulting in a mean state score of 7.7, ranging from $0-23$. For more details on the construction of the CIA SCLD, see Chriqui et al..$^{24}$ The SCLD data are available from the NCI SCLD website: http://www.scld-nci.net.

\section{Percentage smoke-free workplace}

Data concerning smoking regulation at worksites were gathered from the NCI sponsored tobacco use supplement (TUS) to the Current Population Survey (CPS), of the US Census Bureau. The CPS has been conducted monthly with approximately 48000 households in the USA for over 50 years. ${ }^{25}$ Each household is interviewed once a month for four consecutive months. The main purpose of the CPS is to obtain data on employment and labour force changes. The tobacco use supplement of the CPS contains 35 questions, administered to people ages 15 and older. The data used in our study was collected in September 1998, January 1999, and May 1999.

The total number of people sampled in the three months the TUS was administered is 406 432. Of this total, 80788 worked in an indoor area (that is, office, store, warehouse, etc). The percentage that work in a smoke-free area for each state was calculated as those whose workplace has an official smoking policy that restricts smoking completely in both work and common indoor areas, then divided by total indoor workers. The mean was $69.0 \%$ with a range of $50.4-84.2 \%$.

\section{Adult smoking behaviour}

The Behavioral Risk Factor Surveillance System (BRFSS) was established in 1984 to help state health organisations learn state specific information about personal health behaviours. ${ }^{26}$ The data were collected by telephone at monthly intervals. The BRFSS consists of two parts or modules. ${ }^{27}$ The first is a "core" set of questions developed jointly by the states and Centers for Disease Control and Prevention (CDC) that does not change dramatically from year to year. The second set is a "module" that consists of questions of interest to particular states. Adult smoking was a core item and the reliability of the BRFSS for the smoking behaviour question was excellent. ${ }^{28}$

BRFSS data collected in 1998 were used to calculate the percentage of adults smoking in each state. The question asked was "Do you smoke cigarettes now?". This question was posed after receiving a positive answer to the question "Have you smoked 100 cigarettes in your lifetime?". Adults smoking per state had a mean of $23.2 \%$, and ranged from $14.2-30.8 \%$.

Adult smoking behaviour was also measured from the National Household Survey of Drug Abuse (NHSDA), conducted in 1999. This questionnaire, given to the US population, collected data on all types of drug use. ${ }^{29}$ It was sponsored by the Substance Abuse and Mental Health Services Administration.

In 1999, a new computerised data collection system that increased data processing efficiency and privacy to the respondent was implemented. It appears that these surveys are the first to allow valid state level estimates of smoking rates. ${ }^{29}$

Response rates for states varied from $79.9-96.1 \% .{ }^{29}$ A total of 41349 respondents aged 18 years and over were interviewed and are reported on in the study. Rates of "past month cigarette use" were used for this study. Estimates of those answering yes to this question ranged from $19-33 \%$. 


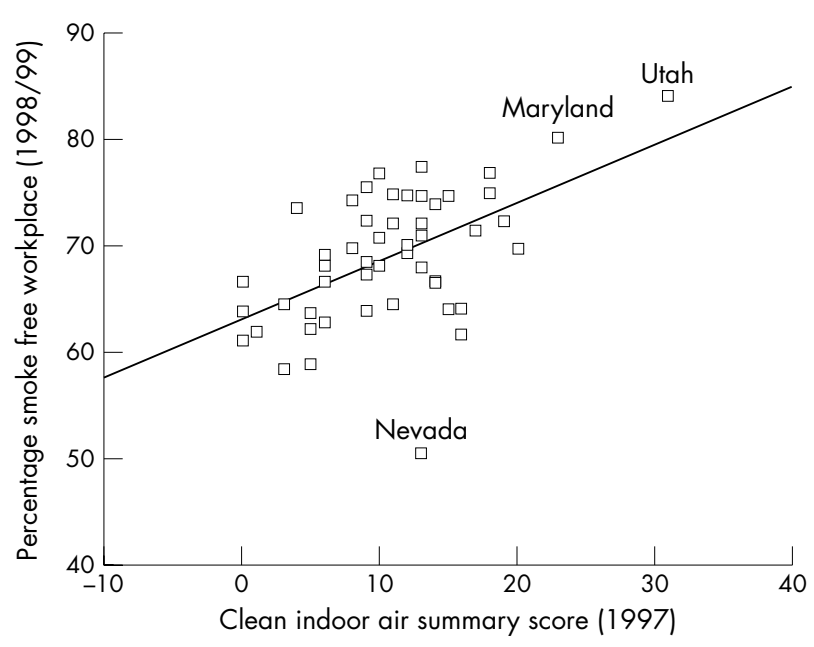

Figure 1 Relation of state's clean indoor air summary scores and \% smoke-free environment.

\section{Youth smoking behaviour}

NHSDA data were used as a source of youth smoking prevalence. Here, a total of 25357 respondents aged 12-17 years were interviewed. Estimates of youth smoking rates by state, measured as "past month cigarette use", ranged from 9-24\%.

Youth smoking behaviour was also measured using data from the Youth Risk Behavior Survey (YRBS). The YRBS was developed by the CDC to monitor important health risk behaviours such as tobacco use among adolescents in high schools around the USA. ${ }^{30}$ Valid state level estimates of youth behaviour were only available for 33 states that conducted statewide surveys apart from the national 1999 YRBS.

The YRBS has been shown to be reliable when administered properly. Reliability coefficients $(\kappa)$ were calculated to verify the test-retest reliability of the questions. $\kappa$ ranged from $0.60-0.80$ for most items, including responses to questions on current smoking status $(r=0.76)$ and initiation of smoking before age $13(r=0.68){ }^{31}$

The total number of respondents from the 1999 statewide YRBS was $67718 .^{30}$ Although overall, school plus individual response rates ranged broadly from $40-78 \%$, student responses were evenly distributed by grade and sex. The prevalence of current smokers ranged from $12-44 \%$, and the proportion of this group who reported purchasing their own cigarettes from a store or gas station ranged from $7.1-37.8 \%$ (representing the youth most likely to be affected by their state's youth tobacco control policies).

\section{Local worksite CIA}

The percentage of workers per state who work in clean indoor air environment were determined by using information published by the American Nonsmoker's Rights Foundation (ANRF).$^{32}$ Local ordinance information has been collected by staff members of the ANRF and covered regulations by local governing bodies and local boards of health since 1985. ANRF collected data from several print and electronic media, including newsgroups, email list servers, and public health newsletters and journals. ${ }^{32}$ These data were then analysed with a standard evaluation instrument before inclusion in the ANRF database. This study used data from 1997.

Communities included in the estimate of local worksite CIA in our study were classified by the ANRF as having either "partial" or "total" ordinances restricting smoking in workplace. Partial ordinance indicates that smoking was still allowed in some areas, while total ordinance indicates that smoking was completely prohibited or only allowed in enclosed, ventilated smoking lounges that workers were not required to enter during their hours of employment. A state level index of CIA policy coverage was created by adding the total population of those communities found to have "total" laws and half the population of communities found to have "partial" laws, then dividing by the population of all communities from that state for which the ANRF reported data, to achieve a percentage of state with local worksite CIA rating. State coverage by local clean indoor air laws ranged from $0-100 \%$. The mean was $26.2 \%$. For more details on the construction of the ANRF database, see National Institutes of Health. ${ }^{32}$

\section{State economic and political characteristics}

Data were collected on the poverty rate of each state in 1997 from the BRFSS. ${ }^{26}$ State tobacco growing status was based on presence of harvestable tobacco acres in each state in $1996 .{ }^{33}$ The dominant political party in each state for 1996/1997 was based on a simple majority of party composition. This majority was determined using the party of the governor and the party majority of state houses and senates. Using these three factors, an interpretable dominant party was easy to ascertain. ${ }^{34}$ Excise tax amounts for 1997 were gathered using SCLD. ${ }^{23}$

\section{Variables and analysis}

Table 1 presents the variables used in this study. The five dependant variables (percentage of state that was smokefree, youth smoking (measured using NHSDA and YRBS) and adult smoking [measured using BRFSS and NHSDA) were measured in 1998 or 1999, while all independent variables reflect 1997 positions to account for lag. Linear regression models were run to assess the relationship of each of the dependent variables to CIA rating, local worksite CIA, poverty rates, and excise tax. Also, analysis of the percentage of state that was smoke-free was stratified using dominant political party in the state (that is, Democrat or Republican) and tobacco growing states. All models were run using CIA rating with and without pre-emption. These results were very similar, therefore only results using the base CIA rating are reported here. Graphical analysis was performed throughout the study to visualise important patterns and check for outliers.

\section{RESULTS}

A significant relationship was found between the proportion of people who work in a smoke-free environment and state CIA score, proportion of the state population covered by local worksite smoking restrictions, people living below the poverty level per state (percentage) and state cigarette excise tax $\left(R^{2}=0.36\right)$ (table 2$)$. State CIA score was the most significant independent variable (fig 1) indicating that it helps explain the variability in the percentage of indoor workers per state who report working in a smoke-free environment. This model was also run using a block method to assess the addition of CIA score to the model. Here, CIA score was shown to be an important addition to the model after accounting for local policy coverage, poverty, and excise tax $($ partial F score $=9.7, \mathrm{p}<0.01)$.

The second dependent variable of interest was percentage of adults who smoked. The model using BRFSS data was significant $(\mathrm{F}=3.1, \mathrm{p}=0.03)$ (table 2$)$. However, only about $21 \%$ of the variability in adult smoking status is explained by state CIA scores, proportion of state that is covered by local workplace smoking restrictions, percentage of people below poverty level, and cigarette excise tax $\left(R^{2}=0.21\right)$. None of the covariates were independently significant. The NHSDA model was somewhat different. With 
a model significance of $\mathrm{p}<0.01$, this data showed that state CIA score was an independently significant covariate $(p=0.01)$ and that $26 \%$ of the variability is adult smoking is explained by the model.

There was a strong relation between youth smoking rates and CIA laws. Analysis of NHSDA data resulted in a robust model $(\mathrm{F}=3.8, \mathrm{p}=0.01)$, as did the YRBS data $(\mathrm{F}=5.4$, $\mathrm{p}<0.01$ ) (table 2). Again, the strongest independent variable for either model was state CIA score-that is, an increase in state CIA score was inversely related to the proportion of youths smoking in a state. Approximately $25 \%$ of the variability in percentage of youths that smoke was accounted for in the NHSDA model $\left(R^{2}=0.25\right)$, while $44 \%$ was accounted for in the YRBS model $\left(R^{2}=0.44\right)$.

Two additional sets of analyses were performed. The first model (percentage smoke-free) was re-run, stratifying by tobacco growing and non-tobacco growing states. The model was significant for both strata (tobacco growing: $\mathrm{F}=3.4$, $\mathrm{p}=0.05 ;$ non-tobacco growing: $\mathrm{F}=2.9, \quad \mathrm{p}=0.04)$. However, there was a difference in the $R^{2}$ values $(0.55 v$ 0.28 , respectively). Next, the data were stratified by Democratic and Republican states. Democratic states reported a higher percentage smoke free than Republican states (Democratic: $\mathrm{F}=4.6, \quad \mathrm{p}=0.01, \quad R^{2}=0.51$; Republican: $\left.\mathrm{F}=2.6, \mathrm{p}=0.06, R^{2}=0.33\right)$.

\section{DISCUSSION}

The goal of this paper was to evaluate the effect of CIA scores, both statewide and local, along with excise tax and poverty rates, on important variables such as reported clean indoor air in the workplace, and adult and youth smoking prevalence. The varied results obtained from these analyses indicate that statewide CIA laws may be the most important indicator.

The first set of analyses indicate that when the association is adjusted for the poverty rate and cigarette excise tax of each state, the state CIA rating was the policy variable most strongly related to the percentage of indoor workers who report working in smoke-free environments. This suggests that state CIA laws have the intended effects. It also indicates that the states with more stringent laws are getting better results, demonstrating that states with weaker (or no) laws might achieve better results by enacting stricter laws. In this analysis, Nevada was an outlier, showing relatively low percentage of people reporting working in a smoke-free environment considering the CIA summary score (fig l). In fact, Nevada routinely proved to be an outlier in these results, probably because of the large amount of workers employed by the gambling industry. This possibly lowered the strength of the relation between these two variables. The decision was made to include all states in each analysis, regardless of their individual properties. Although Nevada and Utah (see below) are statistical outliers, their policies and smoking rates are accurately measured and should be included in the analyses.

Although the two measures of adult smoking are highly correlated (Pearson correlation 0.72, p < 0.01) results for adult smoking seemed to be mixed. The BRFSS data did not show a large influence by a state's clean indoor air summary score. Although both models were significant, the state CIA score was only significantly related to adult smoking when measured using NHSDA data. Other data show an effect of smoking bans on adult smoking behaviour, ${ }^{815} 16$ yet in the case of the BRFSS data this may not be seen because ETS laws have been enacted and influencing adult smoking rates for some time. The BRFSS data may reflect that the majority of decreases in adult smoking prevalence have already happened. It is also important to note that taxes are often shown to affect smoking prevalence rates. Here, there does

\section{What this paper adds}

Environmental tobacco smoke (ETS) is a serious health problem that is affected by policy. There has been implementation of many local and statewide workplace ETS policies. Little is know about how statewide ETS policies relate to ETS exposure in the worksite and smoking prevalence among both adults and youths.

This study shows that when the association is adjusted for local clean indoor air (CIA) laws, poverty rate, and cigarette excise tax of each state, the state CIA ratings have a significant effect on percentage of people who report working in a smoke-free environment, adult smoking, and youth smoking. Because state CIA laws vary so widely, our results support renewed attention on more rigorous statewide ETS policies.

not seem to be any effect. The policy data may not be sensitive enough to pick up this relation.

Both sources of data for youth smoking yielded similar results, showing a relation between the state CIA score and state youth smoking prevalence. It is interesting to note the similarity of the results for these two very different sources of data. The school based YRBS data yields much higher percentages of smoking than the home based NHDSA, yet the correlation of these two data sources was $0.71(p<0.01)$. These results indicate that youths may also benefit from the application of these laws, especially when the laws are directed at the places where youth spend time. These findings link with Wakefield et al, who found that for teens, home and public place bans on smoking were more effective in preventing smoking than bans at school. ${ }^{22}$ One reason for these results may be that strong CIA laws indicate substantial public support. This implies strong anti-tobacco norms in the general public, which may be an effective deterrent to youth smoking. In our analyses, Utah was the largest statistical outlier, showing a high CIA summary score with a remarkably low youth smoking percentage. Influence statistics showed that Utah strengthens the association.

The results from the stratified analysis showed that tobacco growing states have an $R^{2}$ value twice as large as non-tobacco growing states-that is, the impact of state CIA laws was shown to be stronger on those who report working in smoke free workplaces in tobacco growing states. This result may be linked with the relatively higher poverty rates in these states, perhaps because lower income individuals are more affected by increased taxes and price related promotions by tobacco companies. ${ }^{35}$ The tobacco industry has increasingly influenced the policymaking process at the state level through political donations and political action committees. ${ }^{36}$ Although the tobacco industry contributes to both major political parties, over the past two decades there has been a shift towards contributing more money to the Republican party in many states. ${ }^{37}$ This may be the reason our analysis showed a stronger association in Democratic states. Given this pattern, the balance of political party control in a state is an important covariate to examine in a state level analysis of tobacco control policies.

Previous research has shown that local tobacco use laws are very important in reducing non-smokers exposure to ETS. ${ }^{38}$ However, our study suggests that state CIA laws have a large effect, even when controlling for local CIA ordinances. In all models, the state CIA score showed a more significant association with smoke-free workplaces than did local laws. However, we expect that this finding may, in part, be due to the limitations of the local ordinance data and the associated methodology employed to collect and analyse the local 
ordinance data. At the time of this analysis, the ANRF data were the best available source of local ordinance information. The methodology used by ANRF may be described as a passive data collection system. Some information is actively gathered, while other data are sent to the foundation by officials in each state. This is currently the best system available for obtaining this type of data. There is a clear need for a reliable method of identifying, collecting, analysing, and evaluating local CIA laws. The relation between state and local CIA laws with all three of the dependent variables should be further researched, with longitudinal or time series methods. Additionally, it may be helpful to look at a longer, perhaps 3-5 year time period, to check for lag time in the application of some of these laws. Another opportunity for future study would be to examine the actual implementation of these laws and the relation between legislative enactment, implementation, and behavioural outcomes. Similarly, these analyses would be enhanced by incorporating regulatory policy information (for example, How are laws that are passed actually implemented and enforced?).

There are limitations to our study. First, there are the above listed limitations of the ANRF data. Second, in the CPS data that was used, the percentage smoke-free variable was a surrogate for actual exposure to ETS. The CPS is susceptible to some error from non-sampling, including under-representation of males and blacks. Ratio estimation corrects for this partiality, but the CPS, and by extension, the TUS, is still at risk for bias. Third, this study is a cross sectional design, and therefore subject to limitations such as lack of knowledge on temporality. Also, the data were collected at different times, using different sets of people, and in the case of the state and local CIA data, different survey methods. Although there are some questions about the data sources, we expect our results would be verified with a follow up study that asked all of these questions of the same people at the appropriate time.

Our results, especially those concerning the percentage smoke-free and youth data, are provocative. Our results add to the growing body of evidence that supports strong ETS laws, located not only in workplaces, but in all public places. There remains a large variability in the strength of state's CIA laws. We conclude that these laws were a strong determinant of ETS exposure. States should be encouraged to enact even more rigorous policies. The laws that have already been in place appear to be doing what they were designed to do by reducing workplace exposure, and may also be affecting youth smoking.

\section{Authors' affiliations}

K M McMullen, Infection Control, Barnes-Jewish Hospital, St Lovis, Missouri, USA

R C Brownson, D Luke, St Louis University, School of Public Health, St Louis, Missouri, USA

J Chriqui, The MayaTech Corporation, Silver Spring, Maryland, USA

\section{REFERENCES}

1 Centers for Disease Control and Prevention. Exposure to environmental smoke and cotinine levels, Fact sheet. Atlanta, Georgia: CDC, 2002.

2 California Environmental Protection Agency. Health effects of exposure to environmental tobacco smoke. Sacramento, California: CEPA, 1997.

3 Brownson RC, Eriksen MP, Davis RM, et al. Environmental tobacco smoke: health effects and policies to reduce exposure. Annu Rev Public Health 1997; 18:163-85.

4 Pirkle JL, Flegal KM, Bernert JT, et al. Exposure of the US population to environmental tobacco smoke: the Third National Health and Nutrition Examination Survey, 1988 to 1991. JAMA 1996;275:1233-40.

5 Emmons KM, Abrams DB, Marshall RJ, et al. Exposure to environmental tobacco smoke in naturalistic settings. Am J Public Health 1992;82:24-8.

6 Centers for Disease Control and Prevention. Passive smoking: beliefs, attitudes, and exposures - United States, 1986. MMWR Morb Mortal Wkly Rep 1988;39:673-6.
7 US Environmental Protection Agency. The costs and benefits of smoking restrictions. An assessment of the Smoke-Free Environment Act of 1993 (H.R. 3434). Washington, DC: US Environmental Protection Agency, Office of Air and Radiation, Indoor Air Division, 1994.

8 Longo DR, Johnson JC, Kruse RL, et al. A prospective investigation of the impact of smoking bans on tobacco cessation and relapse. Tobacco Control 2001; 10:267-72.

9 Norman GJ, Ribisl KM, Howard-Pitney B, et al. The relationship between home smoking bans and exposure to state tobacco control efforts and smoking behaviors. Am J Hlth Promot 2000;15:81-8.

10 USC § 41706 (2000).

11 Ex. Ord. No. 13058, Aug. 9, 1997, 62 Fed. Reg. 43451.

12 USC $\S 6083$ (2000).

13 American Nonsmokers' Rights Foundation. ANRF Website [Online]. http:// www.no-smoke.org [Accessed 28 July 2003].

14 US Department of Health and Human Services. Healthy People 2010. Volume I, II. Conference Edition. Washington, DC: US Department of Health and Human Services, 2000.

15 Farrelly MC, Evans WN, Sfekas AES. The impact of workplace smoking bans: results from a national survey. Tobacco Control 1999;8:272-7.

16 Woodruff TJ, Rosbrook, Pierce J, et al. Lower levels of cigarette consumption found in smoke-free workplaces in California. Arch Intern Med 1993; 153:1485-93

17 Eriksen MP, Gottlieb NH. A review of the health impact of smoking control at the workplace. Am J Hlth Promot 1998;13:83-104.

18 Wakefield MA, Wilson D, Owen N, et al. Workplace smoking restrictions, occupational status, and reduced cigarette consumption. JOM 1992;34:693-7.

19 Marcus BH, Emmons KM, Abrams DB, et al. Restrictive workplace smoking policies: Impact on nonsmokers' tobacco exposure. J Pub Hlth Pol 1992;13:42-51.

20 Brownson RC, Hopkins DP, Wakefield MA. Effects of smoking restrictions in the workplace. Annu Rev Public Health 2002;23:333-48.

21 Hopkins DP, Briss PA, Ricard CJ, et al. Reviews of evidence regarding interventions to reduce tobacco use and exposure to environmental tobacco smoke. Am J Prev Med 2001;20:16-66

22 Wakefield MA, Chaloupka FJ, Kaufman NJ, et al. Effect of restrictions on smoking at home, at schools, and in public places on teenage smoking: a cross sectional study. BMJ 2000;321:333-7.

23 National Cancer Institute State Cancer Legislative Database. SCLD website [online]. http://www.scld-nci.net/ [Accessed 28 Jan 2002].

24 Chriqui JF, Frosh M, Brownson RC, et al. Application of a rating system to state clean indoor air laws (US). Tobacco Control 2002;11:26-34.

25 US Department of Commerce, Census Bureau, (2001). National Cancer Institute Sponsored Tobacco Use Supplement to the Current Population Survey (1998-1999).

26 Centers for Disease Control and Prevention, National Center for Chronic Disease Prevention and Health Promotion (2002). Behavioral Risk Factor Surveillance System website [online]. www.cdc.gov/brfss/ [Accessed April 2004].

27 Remington PL, Smith MY, Williamson DF, et al. Design, characteristics, and usefulness of state-based behavioral risk factor surveillance: 1981-87. Public Health Rep 1988; 103:366-75.

28 Brownson RC, Jackson-Thompson J, et al. Reliability of information on chronic disease risk factors collected in the Missouri Behavioral Risk Factor Surveillance System. Epidemiology 1994:5:545-49.

29 Kopstein A. Department of Health and Human Services, SAMHSA Office of Applied Studies. Tobacco Use in America: Findings From the 1999 National Household Survey on Drug Abuse, Publication Number (SMA)02-3622., 2001.

30 Centers for Disease Control and Prevention. Youth Risk Behavior Surveillance - United States, 1999. MMWR Morb Mortal Wkly Rep 2000;49(SS-5)

31 Brener NC, Collins JL, Kann L, et al. Reliability of the Youth Risk Behavior Survey questionnaire. Am J Epidemiol 1995;141:575-80.

32 National Institutes of Health National Cancer Institute. Smoking and Tobacco Control Monograph 11, State and Local Legislative Action to Reduce Tobacco Use, NIH Publication No. 00-4804. August 2000.1-2.

33 US Department of Agriculture, Agricultural Statistics Board, National Agricultural Statistics Service. Tobacco: area harvested by state and United States, 1995-1996 and forecasted 1997, cited 5 Feb 1999. http:// usda.mannlib.cornell.edu [Accessed 2 August 2000]

34 Stanley HW, Niemi RG. Vital statistics on American politics, 1997-1998. Washington DC: Congressional Quarterly Press, 1998:20-2.

35 Chaloupka FJ, Cummings KM, Morley CP, et al. Tax, price, and cigarette smoking: evidence from the tobacco documents and implications for tobacco company marketing strategies. Tobacco Control 2002; 1 1(suppl I):i62-72.

36 Luke D, Krauss M. Where there's smoke there's money: tobacco industry campaign contributions and U.S. Congressional voting. Am J Prev Med (in press)

37 Fred M Monardi, Stanton A Glantz. "Tobacco Industry Political Activity and Tobacco Control Policy Making in Pennsylvania: 1979-1996" (December 1 , 1997). Center for Tobacco Control Research and Education. Tobacco Control Policy Making: United States, Paper PA1997. http://repositories.collib.org/ ctcre/tcpmus/PA1997.

38 Pierce JP, Shanks TG, Pertschuk M, et al. Do smoking ordinances protect nonsmokers from environmental tobacco smoke? Tobacco Control 1994;3:15-20. 